\title{
A PERCEPÇÃO DE SERVIDORES DA FACH/UFMS A RESPEITO DOS DESAFIOS DO HOME OFFICE
}

The perception of FACH/UFMS servers with respect to the challenges of home office

\author{
Oséias Freitas de Oliveira Junior. ${ }^{1}$
}

Marcos B. L. Dalmau. ${ }^{2}$

Kelly Cristina Benetti Tonani Tosta ${ }^{3}$

\section{http://dx.doi.org/10.52641/cadcaj.v7i1.526}

RESUMO: Esta pesquisa objetivou compreender como a adoção do trabalho remoto foi percebida pelos servidores da Faculdade de Ciências Humanas da Universidade Federal de Mato Grosso do Sul em função do isolamento social imposto pela pandemia de covid-19. Para alcançar tal objetivo, delineou-se trabalhar com os princípios inerentes a uma pesquisa aplicada, de cunho exploratório e descritivo, bem como abdutivo, por considerar as abordagens quantitativa e qualitativa ao longo de sua realização. Os dados foram coletados no Sistema Eletrônico de Informações - SEI no período de um ano de trabalho remoto (20/03/2020 a 19/03/21) e comparados com o mesmo período do ano anterior. Além disso, outros dados foram coletados via questionários, aplicados junto a 21 profissionais de diferentes funções da referida Faculdade. A análise deles contemplou as técnicas de Bardin (2016) para o exame do conteúdo existente. Apesar de não ter havido unanimidade de percepções, observou-se que a maioria do grupo de servidores se adaptou melhor ao home office, percebendo melhora na qualidade de vida e segurança, enquanto outro grupo se mostrou avesso, vendo essa alternativa como exaustiva e sem qualidade.

Palavras-chave: Trabalho remoto. Home office. Isolamento social. Adaptabilidade.

ABSTRACT: This research aimed to understand how the adoption of remote work, due to the social isolation imposed by the pandemic of Covid-19, was perceived by the employees of the Faculty of Human Sciences of the Federal University of Mato Grosso do Sul To achieve this goal, data from the Electronic Information System - SEI were collected over a period of one year of remote work (03/20/2020 to 03/19/21) and compared with the same period of the previous year. In addition, data from 21 professionals of different functions of the Faculty were collected via questionnaire, which were analyzed with the data collected in the SEI system and through the literature on the subject. Although there was no unanimity of perceptions, it was noticed that most of the group of employees adapted better to the home office, perceiving an improvement in the quality of life and security, while another group showed itself to be averse, seeing such alternative as exhausting and with no positive qualities.

Keywords: Remote work. Home office. Social isolation. Adaptability.

\section{INTRODUÇÃO}

1 Mestrando do Programa de Pós-Graduação em Administração Universitária - PPGAU/UFSC. E-mail: oseias.junior@ufms.br. Orcid: http://orcid.org/0000-0002-3366-1417.

2 Professor do Departamento de Ciências da Administração - CAD/UFSC. E-mail: professordalmau@gmail.com. Orcid: http:// orcid.org/0000-0002-8620-1625.

3 Professora do Programa de Pós-Graduação em Administração Universitária - PPGAU/UFSC. E-mail: kellycbenetti@gmail.com. Orcid: http://orcid.org/0000-0003-0531-5282. 
O ano de 2020 ficou marcado por desafios inéditos em diversos setores da atividade humana. O advento da pandemia de covid-19 resultou na necessidade de adotar medidas extremas e urgentes devido à alta transmissibilidade do coronavírus, o que impôs novas formas de convivência como uma das práticas efetivas contra o contágio, segundo a Organização Mundial da Saúde OMS. A sociedade em geral teve de se adequar, o que provocou muitas alterações no contexto do trabalho tanto em organizações públicas quanto privadas.

Ao adotar o trabalho remoto, pensou-se em um primeiro momento em uma forma de contribuir para o isolamento social, tanto por parte dos trabalhadores como dos consumidores de seus serviços. De certa forma, ainda existem questionamentos quanto à efetividade de tal medida, mas, em função da condição atual do país em face do combate à doença, o que se percebe é que vários tipos de empreendimentos continuam a adotar essa alternativa.

No ramo educacional, é fato que as Universidades têm operado desde então por meio do ensino remoto e/ou híbrido. E, para tanto, muitas das atividades administrativas de suporte igualmente estão sendo realizadas no regime de home office.

Nesse contexto, cita-se a Universidade Federal de Mato Grosso do Sul (UFMS), que implementou o trabalho remoto para os seus servidores a partir do dia 20 de março de 2020, conforme consta na Portaria $n^{\circ} 424$, expedida no dia anterior. Com base nessa determinação, as atividades administrativas e pedagógicas passariam a ser desenvolvidas de modo não presencial, as aulas começariam a ser ministradas por meio de videoconferências e o back office seria realizado na residência de cada servidor. Isso gerou uma forma de trabalho nova e diferente para muitos servidores da instituição, que até então não haviam realizado qualquer tipo de atividade laboral decorrente do teletrabalho e com tais características.

Apenas para fins de esclarecimento, nesta pesquisa adotaram-se os conceitos de teletrabalho, trabalho remoto e home office como sinônimos, ou seja, aqueles que são antagônicos à modalidade comumente denominada trabalho presencial (BRASIL, 2020). Em outras palavras, entende-se tal modelo como a alternativa na qual o funcionário mantém vínculo direto de emprego e hierarquia com uma instituição, mediado pela tecnologia da informação, e desempenha suas atividades fora do espaço físico ocupado pela instituição, podendo fazê-lo de casa ou de outra localidade (BRIDI et al., 2020).

Com base nesse contexto, estabeleceu-se uma delimitação temporal baseada em um intervalo de 364 dias após o início das atividades remotas, período compreendido entre o início do teletrabalho na UFMS e a data da conclusão da coleta de dados, no intuito de responder à seguinte pergunta: como os servidores da Faculdade de Ciências Humanas (FACH) da UFMS estão 
percebendo e enfrentando os desafios impostos por essa modalidade de trabalho, que foi estabelecida em função da necessidade de isolamento social?

Nesse sentido, objetivou-se neste estudo buscar a compreensão sobre o impacto dessa mudança sobre a saúde ocupacional dos profissionais do quadro institucional, visto que existe toda uma dinâmica própria na execução das atividades profissionais no ambiente doméstico, tal como o arranjo e o dimensionamento de espaços físicos adequados e dos equipamentos básicos de trabalho (CASTAÑON et al., 2016).

Como objetivos específicos, delineou-se o seguinte: verificar as questões que envolvem e influenciam o desempenho das atividades laborais dos servidores da FACH/UFMS, em especial onde ocorrem suas interações familiares e conjugais sob o aspecto quantitativo e qualitativo; identificar possíveis fontes de tensão, estresse, assim como adaptação e gerenciamento da carga de trabalho; levantar vantagens e desvantagens percebidas pelos servidores da FACH/UFMS; e sugerir ações visando minimizar possíveis impactos negativos advindos da adoção do home office em relação ao trabalho dos sujeitos abordados na pesquisa.

Para definir qual percurso metodológico seguir para a confecção dessa investigação, utilizou-se a teoria desenvolvida por Saunders, Lewis e Thornhill (2016), com sua estrutura organizada em camadas, passando por diversas categorias, a saber: a filosofia da pesquisa, a lógica, a abordagem do problema, o objeto, a estratégia de coleta e o procedimento de análise de dados.

Diante do exposto, esta pesquisa se configurou como aplicada, e, assim sendo, pautouse pela filosofia interpretativista, uma vez que buscou identificar as percepções dos indivíduos a respeito de um fato que os atingiu, mas que poderia ser percebido de formas muito díspares a partir da vivência de cada um. Já em relação à lógica, adotaram-se os princípios de uma pesquisa exploratória, pois o bome office requerido pelo isolamento social imposto pela pandemia tornouse uma realidade inédita no serviço público.

Para tanto, procurou-se verificar a magnitude dos estudos em torno da temática à luz da análise bibliométrica. A busca sistemática foi realizada por meio da utilização de três bases de dados, sendo elas: a SciVerse Scopus, a SciELO e a Web of Science. As bases foram escolhidas por estarem entre as mais utilizadas para pesquisa científica, uma vez que apresentam literatura mais relevante e cobrem uma ampla variedade de disciplinas (FALAGAS et al., 2008). Para o refinamento da busca nas bases de dados foram utilizados, no campo do título, os termos "bome office", "telework", "teleworking" e "pandemic". Como integradores de busca, a própria plataforma orienta a inclusão de operadores como " $A N D$ ” e "OR". Dessa forma, o caminho da pesquisa resultou da seguinte forma: Título: "home office" or "telework" or "teleworking" and "pandemic", sendo refinado o aspecto temporal para o ano de publicação em 2020. 
Após a leitura dos resumos, foram incorporados à análise 35 trabalhos provenientes das pesquisas nas três bases de dados utilizadas. Entre eles, três tinham suas temáticas ligadas à percepções dos funcionários em relação ao trabalho remoto, e estes formaram a base teórica desta pesquisa, a saber: Raišiene et al. (2020), Madero Gómez et al. (2020) e Seejeen e Cho (2020).

No entanto, os referidos trabalhos, que são pesquisas provenientes de outros países, foram aplicados em contextos distintos daquele da UFMS, o que levou à necessidade de um movimento inverso no sentido da observação indutiva, a fim de formular uma teoria. Desse modo, ao utilizar ambas as lógicas, conclui-se que esta pesquisa é abdutiva (SAUNDERS et al., 2016).

A problemática analisada necessitou de uma investigação cujas abordagens qualitativa e quantitativa se alternaram, sucessivamente, em fases distintas no processo da pesquisa para posterior validação dos dados analisados, o que tornou o entendimento dos resultados mais compreensível (SAUNDERS et al., 2016).

Quanto ao horizonte de tempo, a pesquisa delimitou um período que compreendeu o intervalo de 20 de março de 2020 a 19 de março de 2021 - que, como já visto, corresponde ao primeiro ano da implantação do trabalho remoto para os servidores da FACH.

No entanto, para verificação do fluxo de trabalho, fez-se uma análise por meio da comparação com o mesmo período do ano de 2019/20 (20/03/2019 a 19/03/2020), uma vez que os sujeitos da pesquisa ainda eram os mesmos, bem como as condições objetivas de trabalho eram idênticas. Isso permitiu o dimensionamento do fluxo de trabalho no período equivalente imediatamente anterior à pandemia, visto que era "necessário desenvolver projetos de pesquisa com uma perspectiva longitudinal para poder fazer comparações antes, durante e depois da pandemia". (MADERO GÓMEZ et al., 2020, p. 415).

Pode-se afirmar que este é um estudo de caso, tendo em vista que considerou a análise da dinâmica organizacional da FACH/UFMS diante de múltiplas variáveis que interagem com a problemática investigada, indo, assim, ao encontro do entendimento de Yin (2001). Ademais, levou-se em consideração o fato de um dos pesquisadores ser servidor da instituição estudada, o que configura uma pesquisa que integrou elementos de etnografia, posto que "estuda pessoas em grupos, que interagem entre si e compartilham o mesmo espaço, seja no nível da rua, dentro de um grupo de trabalho, em uma organização ou dentro de uma sociedade" (SAUNDERS et al., 2016, p. 188).

No que tange à definição dos sujeitos participantes da pesquisa, foram delimitados os servidores pertencentes à estrutura burocrática da FACH/UFMS, sendo eles técnicos

\footnotetext{
4 Todas as traduções em citações estrangeiras foram feitas pelos autores.
} 
administrativos em educação e docentes, de modo que pudessem compartilhar suas percepções a respeito do processo de mudança de modalidade do presencial para o bome office.

A atual estrutura conta com 14 técnicos e 9 professores, e 21 deles participaram da pesquisa por meio da resposta ao questionário, o que se considerou um contingente válido e pertinente para o levantamento dos dados.

No tocante à estratégia de coleta de dados, adotou-se o uso de questionários, que foram enviados via e-mail aos servidores objetivando captar sua percepção quanto ao ambiente de trabalho em home office. O questionário foi elaborado com base nos trabalhos de Macedo et al. (2020) e Madero Gómez et al. (2020), relacionados à implantação do bome office e à percepção dos teletrabalhadores, respectivamente.

No questionário foram contemplados 47 itens, divididos em 3 tópicos conceituais, a saber: adaptação e qualidade de vida, com 26 perguntas; infraestrutura e gastos domésticos, com 10 perguntas; percepção de vantagens e vantagens, com 11 perguntas. Os itens foram distribuídos em 6 questões abertas, nas quais o inquirido pôde escrever livremente suas respostas, além de 3 questões com respostas dicotômicas e 38 questões com escalas do tipo Likert, atribuindo-se 1 para "discordo totalmente", 2 para "discordo parcialmente", 3 para "indiferente", 4 para "concordo parcialmente" e 5 para "concordo plenamente". Esses resultados serão apresentados na Tabela 2.

Com base em uma abordagem mista sequencial, na qual as abordagens qualitativa e quantitativa se alternaram sucessivamente em fases distintas, utilizou-se como estratégia complementar de coleta de dados os documentos existentes no Sistema Eletrônico de Informações (SEI), tais como o Plano de Desenvolvimento Institucional (PDI), o Plano de Desenvolvimento da Unidade (PDU) e o relatório da Comissão Setorial de Avaliação (CSA). Também foram considerados documentos oriundos do Portal da Transparência do Governo Federal, por meio de questionário enviado via e-mail, assim como relatórios resultantes de reuniões on line e publicações em redes sociais dos servidores.

Cabe salientar que entrevistas foram realizadas com os supervisores e gestores da FACH no intuito de compreender os pontos de vista inerentes à hierarquia decisória da instituição.

Como técnica de análise de dados, decidiu-se pela lógica de raciocínio de Bardin para o exame do conteúdo. Nesse sentido, na análise quantitativa o que se configurou como informação relevante foi a frequência de ocorrência de determinado evento e/ou característica. Já na análise qualitativa, "foi a presença ou ausência de uma característica de conteúdo ou de um conjunto de características num determinado fragmento de mensagem que é tomada em consideração" (BARDIN, 2016, p. 27). 
Por fim, delimitou-se este trabalho apenas no universo da FACH/UFMS, uma vez que o estudo é resultante de um projeto piloto. Todavia, em função da importância e pertinência do tema junto à instituição, espera-se aprofundá-lo juntamente com outras faculdades pertencentes a tal Universidade.

\section{O HOME OFFICE, O TELETRABALHO E SEUS IMPACTOS: PERCEPÇÕES ORIUNDAS DA PESQUISA BIBLIOMÉTRICA}

Na parte do desenvolvimento, pensou-se em um primeiro momento em contemplar alguns conceitos fundamentais para possibilitar a compreensão e a abrangência do tema em si, bem como dos resultados encontrados.

Conforme apresentado na introdução deste artigo, após a pesquisa bibliométrica, optou-se por considerar como textos-base os estudos de três autores específicos.

O primeiro texto, de Madero Gómez et al. (2020), analisou as percepções dos mitos e do estresse que a necessidade de isolamento social provocou nos trabalhadores que foram obrigados, de forma repentina, a adotar o bome office como modalidade de trabalho.

Os autores evidenciaram o desafio que a situação impôs à organização como um todo, pois, diante da impossibilidade de exercer as atividades de forma convencional, o trabalho remoto "se tornou uma prioridade de solução imediata, com foco no apoio a colaboradores, clientes e fornecedores para que as cadeias de suprimentos de que participam não sejam interrompidas" (MADERO GÓMEZ et al., 2020, p. 404).

Dessa forma, conclui o estudo que, para as organizações, os efeitos da chegada da covid19 tornaram o home office uma ferramenta de aprimoramento profissional e organizacional. No entanto, salientaram os autores que os ambientes físicos de trabalho são espaços de desenvolvimento coorporativos, no qual a atividade conjunta se realiza e possibilita a inovação, de maneira que pesquisas são necessárias para fazer do trabalho remoto uma estratégia viável e bemsucedida para o desenvolvimento dos ambientes produtivos e sociais (MADERO GÓMEZ et al., 2020).

O segundo texto, de Seejeen Park e Yoon Jik Cho (2020), fez uma análise da percepção dos supervisores e teletrabalhadores em comparação com as percepções dos trabalhadores convencionais, no Governo Federal dos EUA. A conclusão foi a de que "os supervisores que trabalham à distância tendem a gastar menos tempo no trabalho que só pode ser realizado no escritório do que os supervisores que não trabalham a distância” (SEEJEEN; CHO, 2020, p. 19), ou seja, a flexibilidade do home office resulta em maior celeridade na execução das tarefas. 
Outro fator importante: quando o supervisor tem uma percepção positiva em relação ao teletrabalho, essa percepção também é positiva quanto aos impactos que a modalidade causa na organização. Tal fato é compreensível, pois muitos funcionários que não têm a oportunidade de teletrabalhar tendem a se mostrar descontentes com a modalidade, uma vez que esta parece um privilégio concedido a alguns beneficiados específicos (SEEJEEN; CHO, 2020).

O terceiro texto, de Raišiene et al. (2020), fez uma pesquisa comparativa entre as percepções dos trabalhadores que já haviam aderido ao home office e os que tiveram de fazê-lo em função da pandemia de covid-19. Em uma pesquisa de cunho quantitativo com indivíduos da Lituânia, foi traçado o perfil que melhor se adaptava ao trabalho remoto e os perfis que tiveram maior dificuldade para engajar-se na modalidade. Os autores concluíram que as percepções são díspares entre os grupos, influenciadas por fatores como: sexo, idade, escolaridade, experiência profissional e experiência de teletrabalho. Porém, um perfil sobressai:

Depois de considerar todas as conclusões do estudo, o seguinte retrato do teletrabalhador mais satisfeito emerge: ela é uma mulher da geração do milênio com diploma de ensino superior, com 4 a 10 anos de experiência profissional, e trabalha em casa dois dias por semana na área de gestão e administração (RAIŠIENE et al., 2020, p. 19).

Em contrapartida, o grupo mais insatisfeito é constituído de homens na faixa etária dos 50 anos, com mais de 20 anos de experiência profissional e que só tiveram contato com o trabalho remoto em função da quarentena. Observou-se também que os funcionários de forma geral passaram a perceber mais positivamente a sociabilização no ambiente profissional do que antes da quarentena (RAIŠIENE et al., 2020).

\section{ESTUDO DE CASO NA FACULDADE DE CIÊNCIAS HUMANAS DA UFMS}

A FACH conta com os seguintes cursos de graduação presenciais: Ciências Sociais Bacharelado; Psicologia - Bacharelado; Filosofia - Licenciatura; História - Licenciatura. E, ainda, os seguintes cursos de pós-graduação: Mestrado em Antropologia Social, Mestrado em Filosofia e Mestrado em Psicologia (Relatório do PDU 2018/2021).

Em relação ao corpo docente, a FACH é composta, atualmente, por 53 professores, todos em regime de dedicação exclusiva. Dentre estes, 9 compõem o quadro de trabalhadores administrativos, sendo 8 coordenadores e 1 diretora. O Corpo Técnico da FACH em 2020/21 é 
composto por 15 técnicos distribuídos nas classes $\mathrm{C}^{5}, \mathrm{D}^{6}$ e $\mathrm{E}^{7}$, como pode ser verificado no Quadro 1:

Quadro 1 - Descrição funcional dos servidores administrativos da FACH

\begin{tabular}{|c|c|c|c|c|}
\hline $\begin{array}{c}\text { Identificação/carga } \\
\text { horária }^{8}\end{array}$ & Cargo & Lotação & Classe/nível & $\begin{array}{c}\text { Ingresso no serviço } \\
\text { público }\end{array}$ \\
\hline A (40 horas) & TAE ${ }^{10}$ & Pós-graduação & $E$ & $02 / 06 / 1980$ \\
\hline B (40 horas) & Assist. em Adm. & Pós-graduação & $E$ & $24 / 10 / 1994$ \\
\hline C (40 horas) & TAE & Secretaria acadêmica & $E$ & $09 / 09 / 2014$ \\
\hline $\mathrm{D}$ (30 horas) & TAE & Apoio pedagógico & $E$ & $01 / 12 / 1994$ \\
\hline E (40 horas) & Psicóloga & Seção de Psicologia & $E$ & $04 / 04 / 2016$ \\
\hline $\mathrm{F}$ (40 horas) & Psicóloga & Seção de Psicologia & $\mathrm{E}$ & $31 / 07 / 2014$ \\
\hline G (40 horas) & Administrador & Coordenação admin. & $E$ & $05 / 02 / 2010$ \\
\hline $\mathrm{H}$ (40 horas) & Assist. em Adm. & Seção de Psicologia & $\mathrm{D}$ & $09 / 09 / 2015$ \\
\hline I (40 horas) & Assist. em Adm. & Seção de Psicologia & $\mathrm{D}$ & $29 / 10 / 2012$ \\
\hline J (40 horas) & Assist. em Adm. & Apoio pedagógico & $\mathrm{D}$ & $06 / 07 / 2018$ \\
\hline K (40 horas) & Assist. em Adm. & Pós-graduação & $\mathrm{D}$ & $26 / 11 / 1986$ \\
\hline L (40 horas) & Assist. em Adm. & Pós-graduação & $\mathrm{D}$ & $03 / 10 / 2014$ \\
\hline M (40 horas) & Assist. em Adm. & Apoio pedagógico & $\mathrm{D}$ & $29 / 10 / 2012$ \\
\hline $\mathrm{N}$ (40 horas) & Auxiliar em Adm. & Portaria & $\mathrm{C}$ & $18 / 05 / 1987$ \\
\hline $\mathrm{O}(\mathrm{DE}){ }^{11}$ & Magistério Superior & Direção & Associado D & $05 / 02 / 1985$ \\
\hline $\mathrm{P}(\mathrm{DE})$ & Magistério Superior & Coord. pedagógica & Adjunto C & $02 / 02 / 2015$ \\
\hline $\mathrm{Q}(\mathrm{DE})$ & Magistério Superior & Coordenação de curso & Associado D & $06 / 10 / 2006$ \\
\hline $\mathrm{R}(\mathrm{DE})$ & Magistério Superior & Coordenação de curso & Titular E & $14 / 03 / 1985$ \\
\hline $\mathrm{S}(\mathrm{DE})$ & Magistério Superior & Coordenação de curso & Adjunto C & $30 / 10 / 2009$ \\
\hline $\mathrm{T}(\mathrm{DE})$ & Magistério Superior & Coordenação de curso & Adjunto $\mathrm{C}$ & $26 / 07 / 2010$ \\
\hline $\mathrm{U}(\mathrm{DE})$ & Magistério Superior & Coordenação de curso & Associado D & $03 / 03 / 2010$ \\
\hline $\mathrm{V}$ (DE) & Magistério Superior & Coordenação de curso & Associado D & $02 / 08 / 2018$ \\
\hline $\mathrm{W}(\mathrm{DE})$ & Magistério Superior & Coordenação de curso & Associado D & $03 / 09 / 2009$ \\
\hline
\end{tabular}

Fonte: PDU, PDI e Portal da Transparência do Governo Federal (2021).

A estrutura administrativa da UFMS vem se modernizando por meio de várias reestruturações e da implantação de novos sistemas, o que aumenta a celeridade dos procedimentos e melhora o resultado final do serviço prestado. No entanto, ela ainda se mostra um pouco ortodoxa nas suas práticas, uma vez que até 19 de março de 2020 não havia qualquer legislação que citasse o trabalho remoto.

\subsection{QUANTIDADE DE PROCESSOS NA FACH/UFMS}

A informatização dos processos é uma prática que visa à eficiência, à agilidade e à

\footnotetext{
5 Técnico administrativo em educação de escolaridade de nível fundamental e médio, conforme especificações da Lei $\mathrm{n}^{\mathrm{o}} 11.091$, de 12 de janeiro de 2005.

6 Técnico administrativo em educação de escolaridade de nível médio completo e/ou médio profissionalizante, conforme especificações da Lei n ${ }^{\circ} 11.091$, de 12 de janeiro de 2005.

7 Técnico administrativo em educação de escolaridade de nível superior específico, conforme especificações da Lei $n^{\circ}$ 11.091, de 12 de janeiro de 2005.

8 Relatório de PDU 2018-2021.

${ }^{9}$ Informações provenientes do Portal da Transparência Federal (http://www.portaltransparencia.gov.br/).

10 Técnico em assuntos educacionais.

${ }^{11}$ Dedicação exclusiva.
} 
publicidade dos atos oficiais. Desse modo, o Governo Federal publicou, em 8 de outubro de 2015, o Decreto $n^{\circ}$ 8.539, que determina o uso do meio eletrônico para a realização de processos administrativos em seus órgãos e em entidades da administração pública federal direta, autárquica e fundacional (BRASIL, 2015).

Com base nessa necessidade, o Tribunal Regional Federal da $4^{a}$ Região desenvolveu um sistema que possibilita a instrução e a tramitação de processos por meio eletrônico, o que garante a economicidade de recursos materiais e de tempo. Define-se como

[...] um sistema de gestão de processos e documentos arquivísticos eletrônicos, com interface amigável e práticas inovadoras de trabalho. Uma das suas principais características é a libertação do papel como suporte físico para documentos institucionais e o compartilhamento do conhecimento com atualização e comunicação de novos eventos em tempo real (ENAP, 2015, p.9.

A esse programa deu-se o nome de Sistema Eletrônico de Informações (SEI), que foi adotado pela UFMS no primeiro semestre de 2017, constituindo-se a partir de então como a única forma de instrução e tramitação de processos internos. Isso significa que todos os atos oficiais administrativos usam o SEI como meio de instrução e tramitação de documentos nos processos internos da UFMS.

Dessa maneira, é representativo verificar qual é o fluxo de trabalho para mensurar a carga laboral sobre os servidores da FACH, uma vez que em home office as atividades se dividiram em tramitar e instruir os processos no SEI e fazer atendimento ao público interno e/ou externo por meio de e-mails e do Whats $A p p$. Esse atendimento é uma atividade residual no montante das tarefas requeridas, como observado pelas gestoras $\mathrm{O}$ e $\mathrm{P}$, ao descreverem as atividades mais complexas, e ratificado pelo servidor $\mathrm{C}$, que classifica esses meios apenas como de comunicação rápida e eventual.

Para analisar o quantitativo de trabalho dos diferentes setores da unidade, foram feitos levantamentos em quatro critérios dos processos digitais: os processos que eram gerados no setor; os documentos gerados no setor; os documentos anexados no setor e os processos tramitados. Esses quatro fatores possibilitavam uma noção da carga de trabalho a que os servidores costumam ser submetidos, pois as atividades executadas passaram necessariamente, ainda que não exclusivamente, pela instrução e/ou tramitação de processos no SEI.

Diante do exposto, na Tabela 1 apresenta-se o quantitativo de processos distribuídos nos setores da FACH/UFMS, fazendo uma comparação entre os dois períodos temporais. 
Tabela 1 - Quantitativo de processos 2019/20 e 2020/21

\begin{tabular}{|c|c|c|c|c|c|c|c|c|}
\hline UNIDADE/SERVIDORES & $\begin{array}{l}\text { P.G. }{ }^{12} \\
2019 / 20\end{array}$ & $\begin{array}{l}\text { P.G. } \\
2020 / 21\end{array}$ & $\begin{array}{l}\text { D.G. }{ }^{13} \\
2019 / 20\end{array}$ & $\begin{array}{c}\text { D.G. } \\
2020 / 21\end{array}$ & \begin{tabular}{|l|} 
D.E.A. ${ }^{14}$ \\
2019/20
\end{tabular} & $\begin{array}{c}\text { D.E.A. } \\
\text { 2020/21 }\end{array}$ & \begin{tabular}{|c|} 
P.T. \\
2019/20
\end{tabular} & $\begin{array}{c}\text { P.T. } \\
2020 / 21\end{array}$ \\
\hline$\overline{\text { DIREÇÃO }}$ & 63 & 36 & 1611 & 962 & 266 & 127 & 964 & 819 \\
\hline COORDENAÇÃO PEDAGÓGICA & 53 & 35 & 299 & 247 & 135 & 166 & 358 & 222 \\
\hline COORDENAÇÃO ADM. & 27 & 12 & 155 & 84 & 124 & 26 & 267 & 139 \\
\hline SECRETARIA ACADÊMICA & 543 & 502 & 419 & 510 & 3464 & 1.449 & 921 & 722 \\
\hline PÓS-GRADUAÇÃO EM ANTROPOLOGIA & 93 & 133 & 233 & 383 & 101 & 209 & 242 & 231 \\
\hline PÓS-GRADUAÇÃO EM PSICOLOGIA & 91 & 102 & 400 & 582 & 160 & 117 & 281 & 217 \\
\hline PÓS-GRADUAÇÃO EM FILOSOFIA & 19 & 30 & 107 & 71 & 69 & 12 & 153 & 114 \\
\hline SEÇÃO DE PSICOLOGIA & 5 & 6 & 11 & 17 & 27 & 18 & 275 & 323 \\
\hline GRAD. CIENNCIAS SOCIAIS & 9 & 6 & 237 & 265 & 67 & 29 & 216 & 189 \\
\hline GRAD. FILOSOFIA & 19 & 40 & 288 & 238 & 54 & 50 & 258 & 235 \\
\hline GRAD. HISTÓRIA & 31 & 3 & 311 & 193 & 141 & 43 & 267 & 199 \\
\hline GRAD. PSICOLOGIA & 25 & 7 & 333 & 272 & 80 & 69 & 263 & 251 \\
\hline MÉDIA DO FLUXO & 81,5 & 76 & 367 & 318,6 & 390 & 192 & & 327 \\
\hline $\begin{array}{l}\text { AUMENTO OU RETRAÇÃO DA QUANTIDADE } \\
\text { DE PROCESSOS }\end{array}$ & \multicolumn{2}{|c|}{$-7,2 \%$} & \multicolumn{2}{|c|}{$+15,19 \%$} & \multicolumn{2}{|c|}{$-103 \%$} & \multicolumn{2}{|c|}{$-7,21 \%$} \\
\hline
\end{tabular}

Fonte: Sistema Eletrônico de Informações - SEI, 21/03/2021.

Ao verificar a média geral da quantidade de processos da $\mathrm{FACH}$, nota-se que na comparação entre os dois períodos há um aumento de 15,19\% no número de documentos gerados. Esse aumento pode ser explicado pelo fato de que várias das questões que antes eram tratadas pessoalmente ou por telefone passaram a ser desenvolvidas por meio formal nos processos. Nesse sentido, as relações interpessoais deram lugar a uma formalidade burocrática mais rígida e impessoal, o que pode causar uma sensação de sobrecarga maior do que realmente representa.

Por outro lado, há também uma pequena queda nos processos gerados e nos processos tramitados, da ordem de 7,2\%, e uma forte retração na quantidade de documentos externos anexados, da ordem de 103\%. A rigor, tem-se uma explicação objetiva, pois essa retração aconteceu especialmente na Secretaria Acadêmica, que diminuiu de 3.464 para 1.449 o número de documentos. Por outro lado, isso se deu em função da diminuição do contato entre o público externo e a estrutura burocrática da instituição, uma vez que esse setor lida com os requerimentos dos acadêmicos. Com as aulas remotas, muitas dessas demandas foram suprimidas.

Para o servidor, essa diminuição representa uma redução da carga de trabalho e do contato interpessoal, ou seja, suas tarefas se tornam mais objetivas, ganhando em impessoalidade e rigidez burocrática; contudo, perde-se em contato pessoal, o que tende a ser prejudicial, ao causar a sensação de uma sobrecarga de trabalho maior do que quantitativamente essa sobrecarga se apresenta. Se por um lado houve um pequeno aumento nas atividades formais desenvolvidas por

12 P.G. - Processos gerados. São aqueles iniciados na unidade.

${ }^{13}$ D.G. - Documentos gerados. Atividade na qual apenas um documento é necessário anexar ou gerar no processo. Normalmente são de resolução rápida e simples.

${ }^{14}$ D.E.A. - Documentos externos anexados aos processos pelo setor. São documentos que precisam ser juntados ao processo e que estão em posse da unidade, ou ela tem acesso ao interessado e assim entra em contato para que este providencie.

${ }^{15}$ P.T. - Processos tramitados para o setor. São aqueles que chegam ao setor para comunicados e informes, mas que não exigem qualquer providência do servidor, salvo tomar ciência. 
meio de processos, isso se deu em função da redução quase absoluta do contato interpessoal entre os servidores. $\mathrm{O}$ servidor $\mathrm{C}$ relata que nesse um ano de home office teve contato com apenas um dos colegas de trabalho.

\subsection{ANÁLISE ABDUTIVA DOS DADOS}

Ao buscar verificar o perfil dos servidores da FACH, encontrou-se um grupo heterogêneo que apresentou disparidades em várias categorias, o que deve ser ponderado antes de perceber as concepções de seus membros sobre o tema em questão.

Dessa maneira, quanto à composição familiar, viu-se que quase metade dos servidores não tem filhos e que a média de pessoas que moram nos domićlios é de 3 pessoas, enquanto, entre os que têm filhos, apenas um servidor tem 5 pessoas no domicílio. Nesse caso, notou-se que as famílias são pequenas e em muitos casos são formadas apenas por um casal, o que facilitaria a adaptabilidade a condições delicadas como é o caso do isolamento social.

Quanto à faixa etária, observou-se que a média de idade é de 42 anos, em uma variação que vai de 30 a 59 anos. Essa variação na faixa etária pode gerar interpretações bem distintas a respeito do mesmo fato, ou seja, alguns indivíduos podem sofrer impactos muito maiores na mudança de modalidade de trabalho, em virtude de perceberem tais fatos de formas bem díspares.

O tempo de serviço público dos servidores da FACH é em média de 13 anos, com uma variação que vai de 2 a 41 anos. Nesse ponto verificou-se uma média baixa no aspecto temporal de trabalho, mas uma alta disparidade entre indivíduos, o que pode gerar um choque de concepções geracionais em relação à cultura, à linguagem e mesmo em relação a concepções políticas e sociais no serviço público. Dessa maneira, esse quesito apresentou tendência a apresentar percepções diferentes sobre os mesmos eventos, pelo fato de os indivíduos verem a realidade sob óticas bem distintas.

A escolaridade foi um quesito que apresentou variação, pois contemplou pessoas de nível médio até o pós-doutorado. Isso impactou no cargo e na função do servidor, restringiu a atuação e delimitou espaços de atuação, remuneração e status na instituição. Mesmo que o cargo seja de nível médio, se o servidor possui um doutorado, por exemplo, gozará de um prestígio mais elevado e terá condições técnicas para ocupar funções mais bem remuneradas e superiores na hierarquia.

Em relação aos cargos e funções, há uma distribuição entre os de nível médio, com 10 servidores; os de nível superior, com 6; e os de magistério superior, com 7, sejam eles na função de coordenação, de gestão pedagógica ou de gestão de cursos de graduação ou de pós-graduação. A diferença de perspectiva entre servidores de nível médio e superior foi pouco percebida, pois eles 
normalmente ocupam funções iguais e desempenham tarefas idênticas. No entanto, perceberamse diferentes concepções sobre a dinâmica da universidade quando se comparou a visão dos servidores técnico-administrativos com a dos servidores do magistério superior: os últimos possuem carreiras distintas, e são eles que executam a atividade-fim da instituição.

Já em relação à remuneração, o que se observou foi um reflexo da diversidade de posições dos itens anteriores, tendo como média o valor de $\mathrm{R} \$ 10.679,05$, mas apresentando variação que vai de $\mathrm{R} \$ 3.653,77$ a $\mathrm{R} \$ 21.108,35^{16}$. Isso impacta na classe social do indivíduo e no status que ele desfruta com seus pares, de forma que, de acordo com a remuneração, o indivíduo tende a se portar como análogo ou antagônico por meio da identificação dos bens de consumo.

Dessa maneira, ao analisar as percepções dos indivíduos não se pode deixar de entender que elas são também resultado dessa heterogeneidade que caracteriza o grupo em questão. Não se pode pensá-los como simples grupo homogêneo que concebe os fatos e eventos sob a mesma ótica e/ou sob os mesmos espaços sociais e organizacionais dos quais são provenientes.

Assim, a partir das respostas ao questionário, foram analisados os dados de forma quantificada e dispostos para serem analisados qualitativamente. A seguir, a Tabela 2 apresenta as respostas dos servidores, os quais foram descritos no Quadro 1, que responderam aos questionários e são identificados de maneira aleatória de A a U, equivalendo cada letra a um dos servidores respondentes. A cada resposta (de 1 a 5) é atribuído o número equivalente na escala Likert, já citada na metodologia.

Tabela 2 - Respostas do questionário especificadas por cada respondente

\begin{tabular}{c|l|c|c|c|c|c|c|c|c|c|c|c|c|c|c|c|c|c|c|c|c|c|c}
\multicolumn{1}{|c}{ Questões } & $\mathbf{A}$ & $\mathbf{B}$ & $\mathbf{C}$ & $\mathbf{D}$ & $\mathbf{E}$ & $\mathbf{F}$ & $\mathbf{G}$ & $\mathbf{H}$ & $\mathbf{I}$ & $\mathbf{J}$ & $\mathbf{K}$ & $\mathbf{L}$ & $\mathbf{M}$ & $\mathbf{N}$ & $\mathbf{O}$ & $\mathbf{P}$ & $\mathbf{Q}$ & $\mathbf{R}$ & $\mathbf{S}$ & $\mathbf{T}$ & $\mathbf{U}$ & $\mathbf{M e ́ d i a}$ \\
\hline 1 & $\begin{array}{l}\text { Você está apto ao } \\
\text { home office }\end{array}$ & 5 & 4 & 5 & 4 & 4 & 4 & 3 & 3 & 5 & 5 & 4 & 1 & 4 & 4 & 4 & 5 & 4 & 4 & 2 & 5 & 5 & 4 \\
\hline 2 & $\begin{array}{l}\text { Espera voltar logo ao } \\
\text { trabalho presencial }\end{array}$ & 1 & 1 & 1 & 2 & 1 & 3 & 5 & 1 & 1 & 1 & 4 & 5 & 3 & 3 & 4 & 1 & 1 & 2 & 2 & 1 & 2 & 2 \\
\hline 3 & $\begin{array}{l}\text { O estresse é maior no } \\
\text { bome office }\end{array}$ & 1 & 1 & 1 & 2 & 2 & 3 & 5 & 1 & 1 & 1 & 4 & 5 & 3 & 3 & 2 & 1 & 1 & 3 & 4 & 1 & 3 & 2 \\
\hline 4 & $\begin{array}{l}\text { Tenho dificuldades de } \\
\text { concentração em casa }\end{array}$ & 1 & 1 & 1 & 4 & 2 & 1 & 5 & 1 & 1 & 1 & 4 & 5 & 1 & 2 & 2 & 1 & 3 & 4 & 3 & 2 & 2 & 2 \\
\hline 5 & $\begin{array}{l}\text { A produtividade a } \\
\text { qualidade do meu } \\
\text { trabalho aumentaram }\end{array}$ & 5 & 3 & 5 & 5 & 3 & 3 & 2 & 1 & 3 & 5 & 3 & 1 & 2 & 3 & 2 & 4 & 3 & 2 & 5 & 3 & 4 & 3 \\
\hline 6 & $\begin{array}{l}\text { O tempo que fico } \\
\text { diante da tela de } \\
\text { computador é menor }\end{array}$ & 1 & 1 & 5 & 2 & 5 & 1 & 2 & 1 & 3 & 1 & 1 & 1 & 1 & 4 & 2 & 2 & 4 & 2 & 1 & 1 & 2 & 2 \\
\hline 7 & $\begin{array}{l}\text { Continuaria o home } \\
\text { office após a pandemia }\end{array}$ & 5 & 5 & 5 & 4 & 3 & 2 & 1 & 1 & 5 & 5 & 1 & 1 & 2 & 3 & 2 & 5 & 5 & 1 & 1 & 3 & 4 & 3 \\
\hline 8 & $\begin{array}{l}\text { Tenho autonomia para } \\
\text { organizar minhas } \\
\text { tarefas e horários }\end{array}$ & 5 & 4 & 5 & 4 & 5 & 4 & 1 & 3 & 5 & 5 & 1 & 1 & 4 & 3 & 4 & 5 & 5 & 4 & 3 & 4 & 4 & 4 \\
\hline 9 & $\begin{array}{l}\text { A qualidade de vida } \\
\text { está melhor }\end{array}$ & 5 & 4 & 5 & 4 & 5 & 2 & 1 & 3 & 5 & 5 & 3 & 1 & 2 & 4 & 2 & 5 & 5 & 1 & 2 & 3 & 4 & 4 \\
\hline
\end{tabular}

${ }^{16}$ Pesquisa feita no Portal da Transparência, considerando a remuneração bruta, em 02/12/2020. 


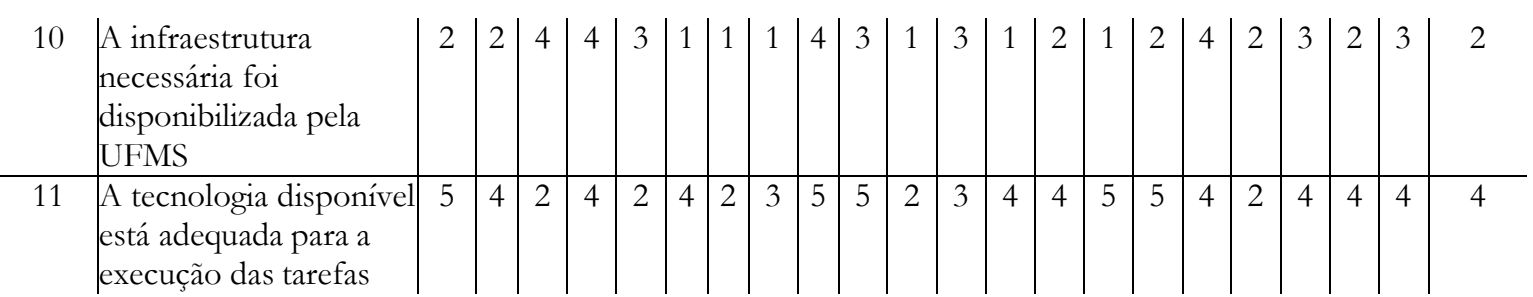

Fonte: Os autores (2021).

Ao analisar os dados fornecidos pelas respostas elencadas, verifica-se a percepção de aspectos positivos e negativos em relação ao trabalho remoto. Dessa forma, vantagens e desvantagens são apontadas de diversas maneiras, mas na média se pode constatar que o servidor percebeu que a experiência foi positiva em vários aspectos.

O primeiro ponto é que os servidores se viram como aptos ao trabalho em home office, ainda que sem treinamento específico nem período de adaptação. Aqui se nota uma confluência entre o interesse institucional e os interesses individuais daqueles que tiveram de se adaptar de forma abrupta a essa modalidade de trabalho. Como demonstrado na linha 1 da Tabela 2, a média dessas respostas foi 4 , o que denota concordância. Ainda que o respondente $\mathrm{L}$ tenha discordado totalmente, 7 dos respondentes concordaram plenamente. Isso também demostra que de modo geral os respondentes receberam bem a mudança naquele momento, que era o do início da pandemia.

Quando indagados se esperam voltar logo ao trabalho presencial, apenas 2 servidores concordaram plenamente, enquanto outros 12 discordaram plenamente e 4 discordaram (linha 2 da Tabela 2). Essa questão pode ser duplamente interpretada, pois aqueles que concordaram que deveriam logo voltar ao trabalho também podem estar simplesmente tentando exprimir que esperam com urgência a volta da normalidade do período pré-pandêmico. Outrossim, os que discordaram podem olhar para a importância sanitária do isolamento e o papel que o trabalho remoto exerce em meio à comunidade universitária.

Quando perguntados se em home office o estresse é maior do que no trabalho presencial (linha 3), apenas 2 responderam que sim, sendo eles os servidores G e L. Para conhecimento, ambos vivem com pessoas do grupo de risco e, nas respostas abertas, mostraram-se totalmente contrários ao trabalho remoto, o que valida suas percepções, uma vez que, de acordo com a composição familiar e o grupo de apoio, o isolamento social impacta de forma muito distinta para cada um dos grupos. Com respostas muito parecidas com as dos que esperavam voltar logo ao trabalho presencial, a sensação de desconforto causado pela pandemia e pela mudança na modalidade de trabalho, aliada a todos os fatores de insegurança, afetou diretamente a percepção dos servidores. 
Outro fator de impacto negativo para o trabalho em bome office é a falta de um ambiente propício para o desenvolvimento das atividades profissionais (linha 4). Nesse caso, novamente se viu uma média que favoreceu a modalidade, o que demostrou que a maioria não tem problemas de concentração para o desenvolvimento das atividades em casa. No entanto, isso não é uma unanimidade, pois os servidores G e L se mostraram incomodados com essa questão, ao responderem que concordam plenamente que a concentração é um problema no ambiente doméstico.

Esses fatores, assim como os anteriores, impactaram diretamente na percepção de produtividade e qualidade do trabalho desenvolvido. Ao se observarem as respostas da linha $5 \mathrm{da}$ Tabela 2, notou-se que elas são quase o inverso da linha anterior, ou seja, os servidores A, C, I e J, que concordaram plenamente que a produtividade e a qualidade foram melhoradas, estavam entre os que discordavam plenamente da dificuldade de concentração em casa, o mesmo acontecendo com a questão do estresse. G e L foram os únicos que discordaram plenamente nesse quesito.

Se a qualidade e a produtividade são percebidas de determinada forma, eventualmente a carga de trabalho tende a sofrer influência dessas variáveis, uma vez que o desconforto ou o conforto resultante delas estará ligado à percepção de que a execução das tarefas será mais ou menos demorada do que na modalidade presencial. Nesse ponto, a média é de discordância, ou seja, a maioria acredita que o tempo gasto para a execução das tarefas na modalidade em bome office é maior do que na modalidade presencial, o que confronta com a posição de Seejeen e Cho (2020, p. 19), pois entendem que "os supervisores que trabalham à distância tendem a gastar menos tempo no trabalho que só pode ser realizado no escritório do que os supervisores que não trabalham à distância”. No entanto, essa percepção pode estar sendo sobrecarregada pela questão da adaptabilidade, o que faz com que os procedimentos passem a ter um caráter mais impessoal e fisicamente distante, gerando, assim, uma sensação de insegurança e dificuldade na realização das tarefas.

Apesar desse resultado, a resposta referente ao bome office dar mais autonomia para a organização e para a execução das tarefas foi de concordância, ou seja, ainda que se percebam as tarefas como mais onerosas, o servidor vê o cumprimento das atividades fisicamente longe de um superior hierárquico como um fator benéfico. Nas linhas 8 e 9 da Tabela 2, pode ser verificada a semelhança entre as respostas sobre autonomia e sobre qualidade de vida, isto é, as percepções parecem convergir entre o sentimento de liberdade hierárquica e o de bem-estar. A média das respostas é de concordância.

No entanto, observa-se que os respondentes A, C, I e J estão entre os que concordaram plenamente, e G e L figuram entre os que discordaram plenamente. Ainda que a média das 
respostas para a carga horária tenha resultado na percepção de que houvera sobrecarga de trabalho, aqui se nota uma contradição, posto que, se a qualidade de vida e a autonomia apresentaram resultados quase idênticos, isso não poderia ser oposto a uma sobrecarga de trabalho. Tal fato acaba sendo reforçado pela análise quantitativa dos dados do SEI no comparativo entre o período de 2019/20, que mostrou a manutenção da quantidade de processos.

O que se observou nas perguntas anteriores foi a tendência de um padrão que sugere a configuração de dois perfis de servidores: A, C, I e J apresentaram quase sempre percepções plenamente favoráveis e G e L quase sempre apresentaram percepções totalmente contrárias ao home office. Com uma média de concordância, os resultados dessa questão mantiveram o padrão das respostas daqueles que se mostraram extremamente favoráveis e dos que se mostraram contrários. Assim, A, C, I e J estão entre os que continuariam em home office após o fim da pandemia, e G e L estão entre os que não continuariam nessa modalidade.

\section{DISCUSSÃO DOS RESULTADOS}

Levando em consideração que a heterogeneidade do grupo estudado é grande, foram comparadas as percepções daqueles que têm filhos em idade escolar e aqueles que não têm, no intuito de verificar qual grupo seria mais receptivo ao trabalho remoto.

Após a análise, verificou-se que o grupo dos que não têm filhos observa, no universo de 37 itens, 11 pontos positivos, enquanto o grupo dos que têm filhos viu no mesmo questionário 26 pontos positivos. Ou seja, nessa comparação se observou que o servidor com filhos em idade escolar é mais propenso a ver vantagens no bome office do que aquele que não tem filhos.

De certa forma isso é compreensível, pois as rotinas pessoais e familiares se alteraram significativamente, sobretudo se for levado em consideração de que muitas crianças também tiveram que se adaptar a uma nova rotina de aprendizado junto às escolas, o que não era algo fácil. Contudo, a questão da segurança dos filhos e a minimização dos riscos de contaminação frente a uma doença na qual se conhecia muito pouco na época, acabou influenciando positivamente na percepção de que a adoção de práticas trabalhistas por tal modalidade seria melhor para o momento.

Outra categorização que merece ser analisada é o gênero, uma vez que homens e mulheres poderiam apresentar percepções díspares em relação ao trabalho remoto. Assim sendo, ao se analisarem as diferenças, observou-se uma lacuna gritante entre os dois grupos. Dos 37 itens analisados, em 28 deles as mulheres tiveram um olhar mais favorável ao bome office do que os homens. Por outro lado, em apenas 6 as percepções foram equivalentes, e somente em 3 elas foram 
mais favoráveis no grupo dos homens. Isso é ratificado por meio das respostas da Tabela 2, onde os respondentes G e L, que apresentaram respostas negativas ao teletrabalho, são homens, e, entre os respondentes A, C, I e J, que demonstraram receptividade elevada à modalidade, 3 são mulheres.

$\mathrm{Na}$ análise notou-se que as servidoras mulheres são mais receptivas ao trabalho remoto do que os servidores homens. No entanto, isso pode ser fruto de valores patriarcais, pois o peso das responsabilidades do lar e da educação dos filhos ainda recai mais sobre os indivíduos do sexo feminino. Nesse contexto, inclusive, a situação apontada por Lemos et al. (2020, p. 399) ocorreu, pois a pandemia provocou a "dispensa das empregadas e faxineiras e obrigou-as a realizar tarefas que nem sempre faziam e o fechamento das escolas e creches demandou mais atenção aos filhos, que ficaram integralmente, em casa". Ou seja, a preferência pelo bome office está ligada a uma sobrecarga de dupla jornada da mulher, que, em trabalho remoto, concentraria suas atividades em um único espaço físico.

Por outro lado, para os representantes do sexo masculino, a situação de não preferência se explica pelos mesmos argumentos apresentados acima, uma vez que muitos homens tiveram que assumir e dividir tais responsabilidades com suas esposas, o que gerou, em certos casos, a "sobrecarga" de trabalho para o qual muitos ainda não estão acostumados. Na situação anterior à pandemia, o trabalho in loco servia como uma válvula de escape e, ao mesmo tempo, de distanciamento de tais questões.

Outra análise comparativa que merece ser feita é entre os docentes que desenvolvem atividades administrativas em relação aos técnico-administrativos em educação, uma vez que dentro desses grupos verificaram-se disparidades subjetivas e objetivas que poderiam vir a ser norteadoras das percepções. Entre elas, pode ser elencado o prestígio institucional, tendo em vista que os docentes pesquisados exercem função de gestão; além do prestígio social e acadêmico, visto que todos possuem doutorado ou pós-doutorado, realidade diferente entre os técnicos; o prestígio hierárquico, posto que exercem função de chefia; e o remunerativo, uma vez que a média da remuneração é de $\mathrm{R} \$ 16.266,93$, enquanto a dos técnicos é de $\mathrm{R} \$ 6.563,78$.

Todos esses fatores poderiam levar a percepções diferentes. No entanto, ao comparar as visões dos docentes/gestores e os TAEs, verificou-se pouca disparidade entre os dois grupos, pois, dos 37 itens analisados, em 17 deles os técnicos foram mais receptivos ao trabalho remoto, enquanto em 13 as concepções foram iguais e em apenas 7 os docentes apresentaram percepções mais favoráveis ao teletrabalho.

Nessa análise, notou-se que ambos os grupos apresentaram percepções parecidas, porém os TAEs apresentaram tendência maior a aceitar o bome office. As razões são inúmeras, mas é evidente que produtividade, concentração, administração da rotina de trabalho, economia com 
alimentação e transporte influenciaram significativamente tais percepções. Além do mais, muitos destes profissionais já estavam acostumados com o tipo de trabalho mais virtualizado, afinal o acesso aos sistemas universitários já ocorre desta forma. Assim, a aclimatação a uma "nova realidade" laboral foi mais fácil de se assimilar.

No caso dos docentes, ainda que o questionário fosse explícito em relação às atividades de gestão, verificou-se um temor de que após o período de pandemia, algumas aulas continuassem na modalidade à distância, o que pode ser verificado na troca de mensagens de Whats $A p p$ com a servidora R (docente/gestora). Ao ser convidada a responder ao questionário, ela disse: “ok... eu temo que isso seja usado para acabar conosco", o que demonstrou certo receio de que a modalidade de trabalho remoto emergencial seja parte de uma estratégia capaz de prejudicar o ensino. Nesse sentido, ao contrário dos TAEs, a necessidade de se preparar para uma nova realidade laboral, bem como a sua devida aclimatação, influenciou a percepção de diversos docentes neste caso, fazendo com que houvesse naturalmente uma sobrecarga de atribuições.

Apesar do que foi comentado no parágrafo anterior, salienta-se que muitas das atividades dos docentes - estejam eles na condição de gestores ou não - são naturalmente desenvolvidas em casa, afinal eles não têm a necessidade de registrar ponto de presença. Contudo, mesmo que muitos entendam o home office apenas como o ato de dar aulas remotamente, é fato que todos se depararam com a dificuldade de conciliar os novos afazeres domésticos com suas rotinas laborais. Além disso, não se pode deixar de mencionar que houve inicialmente um aumento da carga de trabalho para que os docentes pudessem planejar e estruturar suas aulas de forma diferente das existentes e praticadas no meio presencial, o que fez com que houvesse uma forçosa adaptação e/ou geração de novas competências para tanto.

Um fato curioso é que os técnicos, por sua vez, visualizaram o trabalho remoto como um benefício, uma vez que na modalidade presencial há um rígido controle de frequência por meio de ponto eletrônico, e, quando se comparam com os docentes em relação ao controle de presença, reclamam da disparidade de tratamento institucional.

Porém, esta percepção tende a ser diferente em relação ao perfil dos respondentes, uma vez que em conversa com a servidora técnica J, ela argumentou: "estou adorando o trabalho remoto, sobra mais tempo para resolver suas questões e o trabalho rende mais", enquanto o servidor técnico G pontuou: “não vejo a hora de voltar tudo ao normal, pois é muito complicado não poder vir para a universidade e se desligar um pouco". Analisando o perfil deles, inferiu-se que tais respostas poderiam estar aderentes às suas trajetórias profissionais, uma vez que a servidora $\mathrm{J}$, por exemplo, é mais jovem e possui apenas 2 anos de serviço público. Ela passou a maior parte de sua vida profissional na iniciativa privada, apresentando, assim, um perfil mais independente e 
proativo. Outrossim, o servidor G é mais velho e tem 12 anos de trabalho no serviço público, apresentando, inclusive, um perfil mais conservador e reativo, o que pode dificultar o desempenho das atividades em casa.

Em relação às vantagens e desvantagens do trabalho remoto, foram apontadas proposições reunidas e categorizadas com base em 5 indicadores propostos por Macedo et al. (2020). O Quadro 2 apresenta os resultados:

Quadro 2 - Resultado das questões abertas dos questionários sobre vantagens e desvantagens

\begin{tabular}{|c|c|c|c|c|c|}
\hline $\begin{array}{l}\text { Indicadores } \\
\text { /Pontos }\end{array}$ & ESTRUTURAIS & BEM-ESTAR & PESSOAIS & PROFISSIONAIS & PSICOLÓGICOS \\
\hline \multirow{4}{*}{$\begin{array}{c}\mathbf{V} \\
\mathbf{A} \\
\mathbf{N} \\
\mathbf{T} \\
\mathbf{A} \\
\mathbf{G} \\
\mathbf{E} \\
\mathbf{N} \\
\mathbf{S}\end{array}$} & \multirow[t]{4}{*}{$\begin{array}{l}\text { 1. Interação com } \\
\text { técnicos de outros } \\
\text { campi da UFMS }\end{array}$} & $\begin{array}{l}\text { 1. Menor carga } \\
\text { de trabalho }\end{array}$ & $\begin{array}{l}\text { 1. Convívio } \\
\text { familiar } \\
\text { aumentou }\end{array}$ & $\begin{array}{l}\text { 1. Organização das } \\
\text { atividades }\end{array}$ & $\begin{array}{l}\text { 1. Menos } \\
\text { desgastante }\end{array}$ \\
\hline & & $\begin{array}{l}\text { 2. Menor } \\
\text { tempo no } \\
\text { trânsito }\end{array}$ & $\begin{array}{l}\text { 2. Não vejo } \\
\text { qualquer } \\
\text { desvantagem }\end{array}$ & $\begin{array}{l}\text { 2. Aprendizagem de } \\
\text { novas tecnologias }\end{array}$ & 2. Maior privacidade \\
\hline & & $\begin{array}{l}\text { 3. Qualidade } \\
\text { de vida } \\
\text { aumentou }\end{array}$ & & $\begin{array}{l}\text { 3. Maior autonomia } \\
\text { e produtividade }\end{array}$ & $\begin{array}{l}\text { 3. Capacidade de } \\
\text { foco e concentração }\end{array}$ \\
\hline & & $\begin{array}{l}\text { 4. Manteve a } \\
\text { segurança } \\
\text { quanto à covid }\end{array}$ & & $\begin{array}{l}\text { 4. Flexibilidade de } \\
\text { horários }\end{array}$ & $\begin{array}{l}\text { 4. Diminuiu o } \\
\text { estresse com } \\
\text { cobranças da chefia }\end{array}$ \\
\hline \multirow{5}{*}{$\begin{array}{c}\text { D } \\
\text { E } \\
\text { S } \\
\text { V } \\
\text { A } \\
\mathbf{N} \\
\mathbf{T} \\
\text { A } \\
\text { G } \\
\mathbf{E} \\
\mathbf{N} \\
\text { S }\end{array}$} & $\begin{array}{l}\text { 1. Faltou } \\
\text { comunicação entre } \\
\text { os setores }\end{array}$ & $\begin{array}{l}\text { 1. Aumento de } \\
\text { demanda }\end{array}$ & $\begin{array}{l}\text { 1. Falta de } \\
\text { interação } \\
\text { social }\end{array}$ & $\begin{array}{l}\text { 1. Disponibilidade } \\
\text { permanente }\end{array}$ & $\begin{array}{l}\text { 1. Aumento do } \\
\text { estresse }\end{array}$ \\
\hline & $\begin{array}{l}\text { 2. Atendimento de } \\
\text { serviço ficou } \\
\text { péssimo }\end{array}$ & $\begin{array}{l}\text { 2. Sobrecarga } \\
\text { de trabalho. }\end{array}$ & $\begin{array}{l}2 . \\
\text { Dificuldade } \\
\text { para separar } \\
\text { a vida } \\
\text { pessoal da } \\
\text { profissional }\end{array}$ & $\begin{array}{l}\text { 2. Diminuição da } \\
\text { produtividade }\end{array}$ & $\begin{array}{l}\text { 2. Aumento da } \\
\text { ansiedade pela falta } \\
\text { de limites de } \\
\text { horários e } \\
\text { cobranças }\end{array}$ \\
\hline & $\begin{array}{l}\text { 3. Urgência nas } \\
\text { solicitações }\end{array}$ & $\begin{array}{l}\text { 3. Demandas } \\
\text { de trabalho } \\
\text { fora do horário }\end{array}$ & $\begin{array}{l}\text { 3. Desgaste } \\
\text { do } \\
\text { equipamento } \\
\text { pessoal } \\
\text { próprio }\end{array}$ & $\begin{array}{l}\text { 3. Prejuízo na rotina } \\
\text { institucional }\end{array}$ & 3. Saúde psíquica \\
\hline & $\begin{array}{l}\text { 4. Infraestrutura } \\
\text { não adequada para } \\
\text { o trabalho }\end{array}$ & & $\begin{array}{l}\text { 4. Não há } \\
\text { qualquer } \\
\text { vantagem! }\end{array}$ & & $\begin{array}{l}\text { 4. Maior } \\
\text { possibilidade de } \\
\text { distração }\end{array}$ \\
\hline & $\begin{array}{l}\text { 5. Aumento das } \\
\text { despesas com água, } \\
\text { luz, internet }\end{array}$ & & & & \\
\hline
\end{tabular}

Fonte: Questionário enviado aos servidores (2020).

Ao pontuar as vantagens e desvantagens apontadas pelos servidores, foram percebidas visões antagônicas a respeito do assunto. Dessa maneira, serão ponderados os indicadores de modo pormenorizado.

Quanto à infraestrutura, constatou-se o caráter emergencial da medida de adoção do trabalho remoto, uma vez que, ao mudar para tal modalidade, os servidores não contaram 
imediatamente com o respaldo de infraestrutura física por parte da UFMS. Como exemplo, cita-se o servidor que precisou de computador e teve de apresentar requerimento para conseguir o equipamento, ou então deveria usar sua própria estrutura, o que levou a uma sensação de abandono institucional.

Ao apontar a falta de uma estrutura física adaptada ao trabalho e o aumento nas despesas de energia e internet, assim como uma piora no atendimento e na comunicação entre setores, os servidores identificaram que tais pontos se configuraram como negativos. A rigor, entendeu-se que eles deveriam ter sido analisados dentro do âmbito da pandemia e da urgência de adotar soluções que ainda não haviam sido pensadas, ou seja, o ineditismo da situação requereu ações emergenciais e a adoção de alternativas que geraram críticas por parte dos servidores.

No indicador de bem-estar, verificaram-se entre as vantagens a diminuição da carga de trabalho, o menor tempo no trânsito, o aumento na qualidade de vida e a segurança em face da covid-19. Nesses aspectos foram constatados fatores objetivos quanto ao trânsito e à segurança do isolamento social, mas também fatores subjetivos quanto à carga de trabalho, que, como visto anteriormente, na análise dos dados do SEI, apresentaram uma leve queda. Porém, essa percepção se justifica pelo fato de que, em um ambiente de maior concentração e menos interrupção, as tarefas sejam desenvolvidas com maior rapidez e objetividade, o que dá a impressão de diminuição do quantitativo de trabalho.

Continuando no mesmo indicador, em relação à qualidade de vida, essa percepção pode estar atrelada ao que foi exposto no subitem anterior, referente ao registro do ponto e ao peso hierárquico que a presença física impõe.

Já em relação às desvantagens, foram apontados o aumento da demanda e sobrecarga de trabalho e a demanda fora do horário. Como já discutido, o volume de trabalho permaneceu o mesmo. Contudo, os indivíduos que têm maior dificuldade de concentração no ambiente doméstico perceberam como sobrecarga as tarefas que usualmente são desenvolvidas na modalidade presencial na instituição.

No que tange à demanda fora do horário, é importante observar que todos os servidores apontaram que respondem e-mails e mensagens de Whats $A p p$ fora do horário de trabalho, o que demostrou um vício cultural da organização. Todavia, pode ser visto como uma transferência de responsabilidade do indivíduo para a instituição, posto que houve também a concordância de que o home office é benéfico por flexibilizar horários. Em outras palavras, pode-se aferir que, quando há uma flexibilização do horário, isso se estende para o horário de descanso, por exemplo, gerando uma flexibilidade diferenciada se comparada ao meio presencial.

Entre as pontuações pessoais, citou-se que o aumento do convívio familiar amentou. Esse 
ponto pareceu ser comum entre os servidores, pois, ainda que não apontados por todos, constatouse nos stories do Whats App e do Instagram um aumento das atividades de lazer entre familiares e grupos de amigos. Assim sendo, essa interação possibilitada pelo trabalho remoto atingiu não apenas aqueles que desejavam mais contato com os membros da família, mas também os indivíduos solteiros e sem filhos, que encontraram nessa modalidade maior possibilidade de interação social por meio das tecnologias, o que, considerando os dias atuais, pouco mudou.

Porém, um fato curioso deve ser ponderado: o convívio entre os pares, ou melhor, a falta dele com base nos parâmetros inerentes ao meio presencial fez com que houvesse, inicialmente, uma maximização da utilização das tecnologias virtuais para "diminuir a distância". Contudo, o uso frequente fez com que o entusiasmo decorrente da manutenção de tais contatos pessoais e profissionais caísse com o passar do tempo, porque acabou gerando uma sobrecarga nas rotinas pessoais, além de que naturalmente não substitui as interações presenciais.

Nesse sentido, o parágrafo anterior pode ser entendido como uma possível desvantagem apontada. Cabe salientar que houve um reflexo das características específicas dos dois grupos. Para tanto, verificou-se que a falta de interação social, quando destacada, atingiu principalmente os indivíduos solteiros que moram sozinhos. Em outras palavras, esse sentimento pareceu ser mais manifestado naqueles que veem no trabalho um momento de interação social e na vida privada um momento de isolamento e privacidade, o que fez com o que o bome office se tornasse um peso quanto à menor interação social.

No que se refere ao apontamento da dificuldade de separação da vida pessoal e profissional, compreendeu-se que é um problema compatível com o indivíduo que geralmente mora com a família e desempenha suas atividades profissionais em meio às atividades familiares. De toda forma, como discutido anteriormente, conclui-se que o grupo das pessoas que têm filhos demonstra maior aptidão ao teletrabalho, o que indica que esse apontamento é isolado ou de menor importância em meio às percepções positivas.

Nos indicadores profissionais, os servidores apontaram o crescimento profissional nas atividades do trabalho remoto, o que chama a atenção, pois muitos passaram a ocupar o tempo aprendendo a usar novas tecnologias, e talvez não fizessem isso no presencial. Afinal, com o home office, a necessidade de dominar novas ferramentas de comunicação para trocas de mensagens e videoconferências se fez imprescindível. Da mesma maneira, as demais questões pontuadas mostraram um indivíduo que tende a buscar mais liberdade organizacional e menos relações hierárquicas.

No que se relaciona às desvantagens de tal indicador, aqui aparece a dicotomia entre a flexibilidade e a disponibilidade permanente, assim como as percepções conflitantes entre o 
aumento e a diminuição da produtividade. O importante a destacar é o prejuízo para a rotina institucional, o que parece ser uma realidade, pois o indivíduo parece ter perdido parte considerável de seu vínculo com a cultura organizacional existente na instituição. Isso tende a provocar o distanciamento de ideais e do código ético, ou seja, os valores cultivados no convívio começam a se perder pela superficialidade das reuniões on line, por exemplo.

Nos indicadores classificados como psicológicos, as vantagens apontadas demonstraram o alívio da ausência, ou seja, havia um peso que o indivíduo carregava ao ser obrigado a comparecer todos os dias à repartição e conviver rotineiramente com as mesmas pessoas. Isso gera o chamado peso da rotina, que vai da privacidade até o menor estresse com a cobrança da chefia, ou seja, no bome office o servidor pareceu se sentir menos pressionado em seu ambiente doméstico.

Enquanto isso, as desvantagens apontadas convergem para questões relativas à flexibilidade nos horários e nas relações de trabalho, que trazem consigo bônus e ônus para o servidor. Já as questões da saúde psíquica e da maior possibilidade de distração foram apontamentos isolados que não apareceram em outras formas de coleta de dados, mas que se configuraram como reais, na medida que alguns servidores se mostraram adversos a qualquer nuance trazida pelo trabalho remoto.

\section{CONCLUSÕES}

Este artigo buscou captar as percepções dos servidores da FACH/UFMS em relação ao trabalho em home office. Com esse objetivo, fez-se uma pesquisa bibliométrica que mensurou a produção sobre os assuntos no período do ano de 2020, e o resultado é que poucos estudos trataram sobre a temática do home office em meio à pandemia. No caso do Brasil, nenhum texto foi encontrado que relacionasse a necessidade do trabalho remoto ao isolamento social.

Apoiado nos dados coletados e analisados, pode-se concluir que o perfil médio do servidor da FACH/UFMS tende a aceitar o trabalho remoto emergencial, mas não se vê como um trabalhador permanente dessa modalidade. Ainda que se vejam qualidades no bome office, verificouse que o indivíduo em geral é inclinado a exigir rigidez nos horários de descanso e a ver como bemvinda a flexibilização do horário de trabalho. Já na comparação entre alguns grupos, observou-se que as mulheres são mais receptivas do que os homens, assim como, da mesma forma, os indivíduos que têm filhos em idade escolar perceberam mais vantagens do que aqueles que não têm filhos em idade escolar. No comparativo entre os docentes gestores e os TAEs, notou-se que estes últimos observaram mais positivamente o trabalho remoto do que os primeiros. 
Ao se analisar a situação atual após um ano do início da pandemia, constata-se que não se vislumbra um desfecho rápido e definitivo, o que pode requerer novos períodos longos de isolamento social ou períodos intermitentes de isolamento. Isso faria com que o bome office tivesse de passar de modalidade emergencial para modelo recorrente, o que exigiria uma preparação mais completa.

Entende-se, diante dos fatos, que a FACH/UFMS deveria incentivar com maior vigor a qualificação dos servidores para melhor adaptação a essa modalidade, o que poderia ocorrer por meio de treinamentos ofertados pela própria instituição ou por outros órgãos da administração pública. Evidentemente, os treinamentos deveriam ser oferecidos por meio do ensino à distância, o que, em função dos investimentos pessoais feitos pelos respondentes quanto à capacitação em novas tecnologias, talvez pudesse ser bem recebido.

Outrossim, a FACH, por intermédio dos gestores, deverá identificar os servidores que apresentam maior dificuldade adaptativa e oferecer suporte operacional e psicológico, tendo em vista o risco de haver baixas devido ao estresse emocional que o isolamento produz, bem como a dificuldade de conciliar as rotinas caseiras com as profissionais. Da mesma forma, poderiam ser identificadas e balanceadas as possíveis sobrecargas laborais, em especial as relacionadas ao público feminino.

Por fim, destaca-se que o objetivo deste trabalho foi alcançado. Evidentemente o quantitativo amostral foi pequeno e não pode ser considerado representativo para a instituição como um todo. Contudo, por ser parte de um projeto piloto, entende-se que a importância desta pesquisa está na análise e na metodologia empregada, que poderá ser replicada e aprimorada em estudos futuros que abordem a temática aqui desenvolvida.

\section{REFERÊNCIAS}

BARDIN, Laurence. Análise de conteúdo: ed. rev. e ampl. São Paulo: Edições 70, 2016.

BRASIL. Presidência da República. Decreto $\mathbf{n}^{\circ}$ 8.539, de 8 de outubro de 2015. Dispõe sobre o uso do meio eletrônico para a realização do processo administrativo no âmbito dos órgãos e das entidades da administração pública federal direta, autárquica e fundacional. Brasília, 2015.

BRASIL. Ministério da Economia. Gabinete do Ministro. Instrução Normativa $\mathbf{n}^{\mathbf{0}} \mathbf{6 5}$, de 30 de julho de 2020. Estabelece orientações, critérios e procedimentos gerais a serem observados pelos órgãos e entidades integrantes do Sistema de Pessoal Civil da Administração Federal - SIPEC relativos à implementação de Programa de Gestão. Brasília, 2020. 
BRIDI, Maria Aparecida; BOHLER, Fernanda Ribas; ZANONI, Alexandre Pilan. Relatório técnico-científico da pesquisa: o trabalho remoto/home-office no contexto da pandemia covid-19. Curitiba: UFPR: GETS: REMIR, 2020.

CASTAÑON, José Alberto Barroso; CRUZ, Tairine Cristine Bertola; CARVALHO, Juliana Lodi; RAGONE, Guilherme Nogueira. O home office e a ergonomia nas condições de trabalho e saúde de arquitetos e engenheiros. In: $1^{\circ}$ CONGRESSO INTERNACIONAL DE ERGONOMIA APLICADA. São Paulo: Blucher, 2016. p. 643-654.

ESCOLA NACIONAL DE ADMINISTRAÇÃO PÚBLICA (ENAP). Manual do SEI - Enap Sem Papel. Jun. 2015.2 Disponível em: http://sempapel.enap.gov.br/wpcontent/uploads/2015/06/Projeto-Manual-Enap-semPapel.pdf. Acesso em: 23 set. 2021.

FALAGAS, Matthew E.; PITSOUNI, Eleni I.; MALIETZIS, George A.; PAPPAS, Georgios. Comparison of PubMed, Scopus, Web of Science, and Google Scholar: strengths and weaknesses. The FASEB Journal, v. 22, issue 2, fev. 2008. Disponível em: 10.1096/fj.07-9492LSF. Acesso em: 23 set. 2021.

LEMOS, Ana Heloísa da Costa; BARBOSA, Alane de Oliveira; MONZATO, Priscila Pinheiro. Mulheres em home office durante a pandemia da covid-19 e as configurações do conflito trabalhofamília. Revista de Administração de Empresas - RAE, v. 60, n. 6, nov./dez. 2020.

MADERO GÓMEZ, Sergio; ORTIZ MENDOZA, Oscar Eliud; RAMÍREZ, Jacobo; OLIVASLUJÁN, Miguel R. Stress and myths related to the covid-19 pandemic's effects on remote work. Management Research - Journal of the Iberoamerican Academy of Management, v. 18, n. 4, p. 401-420, 2020.

RAIŠIENE, Agota Giedré; RAPUANO, Violeta; VARKULEVIČIŪTĖ, Kristina; STACHOVÁ, Katarína. Working from home: who is happy? A survey of Lithuania's employees during the covid19 quarantine period. Sustainability, 12(13), 5332, 2020. doi:10.3390/su12135332.

SAUNDERS, Mark N. K.; LEWIS, Philip; THORNHILL, Adrian. Research methods for business students. Harlow: Pearson Education, 2016.

SEEJEEN, Park; CHO, Yoon Jik. Does telework status affect the behavior and perception of supervisors? Examining task behavior and perception in the telework context. The International Journal of Human Resource Management, 2020. doi:10.1080/09585192.2020.1777183.

UNIVERSIDADE FEDERAL DE MATO GROSSO DO SUL (UFMS). Reitor. Portaria $\mathbf{n}^{\mathbf{0}}$ 424, de 19 de março de 2020. Dispõe sobre a adoção do teletrabalho em função da pandemia. Campo Grande, 2020. Disponível em: https://ppgdip.ufms.br/files/2020/03/Portaria-424.pdf. Acesso em: 19 mar. 2021.

YIN, Robert K. Estudo de caso: planejamento e métodos. Porto Alegre: Bookman, 2001. 